\title{
Past exposure to asbestos and combustion products and incidence of cancer among Finnish locomotive drivers
}

Pekka Nokso-Koivisto, Eero Pukkala

\begin{abstract}
Locomotive drivers in the steam engine era were exposed to asbestos during their vocational training for two years while training in workshops. Later in their career they had exposure to coal and diesel combustion products. To assess the level of earlier exposure historical working conditions were reconstructed and hygienic conditions were measured. The average exposure to asbestos (mainly anthophylline) fibres $>5 \mu \mathrm{m}$ was 5.0 fibres/cm ${ }^{3}$. Incidence of cancer in a cohort of 8391 members of the Finnish Locomotive Drivers' Association, 195391, was analysed. The incidence of lung cancer and also total cancer was below the national average, probably due to the low prevalence of smoking among the drivers in the steam engine era. $A$ fourfold risk of mesothelioma was found, most likely caused by exposure to asbestos. Also the observed $1 \cdot 5$-fold incidence of non-melanoma skin cancer and 1.7-fold risk of cancer of the oral cavity and pharynx may be related to occupation.
\end{abstract}

(Occup Environ Med 1994;51:330-334)

This study arose from a case of mesothelioma in a locomotive driver, and from concern that conservation and recycling of old locomotives and coaches causes exposure to asbestos. During the steam engine era all trainee locomotive drivers in Finland were exposed to asbestos in the railway workshops. When working in traffic operations, the drivers were exposed to combustion products and to coal tar. New diesel locomotive drivers are exposed to exhaust fumes from the engine.

Asbestos exposure is suspected to have caused an increased risk of mesothelioma and lung cancer among locomotive drivers and other railway workers. ${ }^{1}$ Combustion products of coal and diesel have been reported to be associated with lung cancer ${ }^{2}$ and cancer of the bladder. ${ }^{3-5}$ The incidence of non-melanoma skin cancer is increased among people exposed to combustion products of $\operatorname{coal}^{6}$ and creosote. $^{7}$ Cancers of the buccal cavity and pharynx and lymphatic tissue have been found in excess among railway workers. ${ }^{48}$

Our study has two components. The lifelong work exposures of locomotive drivers, as a constellation of occupational causes of cancer, were investigated through measurements of hygienic conditions in the steam engine era and through evaluating routine hygienic investigations of working conditions in the diesel engine era. Also, the incidence of cancer among Finnish locomotive drivers was compared with that of the total Finnish population from 1953 to 1991 .

\section{Methods}

ASSESSMENT OF EXPOSURES

All locomotive drivers of the Finnish state railways are educated according to defined curricula, which before the 1970 s included two years practising in a railway workshop. The main part of the training took place in the engine maintenance department of the workshop. In the 1960s steam engine maintenance gradually ended. The drivers who started their training at the beginning of the 1970s did not take part in steam boiler upkeep. The trainees graduated to assistant locomotive drivers, started regular train operations, and were later promoted to locomotive drivers.

To study the hygienic conditions in the steam engine era the working conditions were reconstructed in two workshops with the assistance of older workers who used to take part in the earlier standard procedures. During the procedure the outer covers of the boilers of two engines were dismantled. Asbestos layers were loosened and torn away and collected in separate containers. The process looked dusty. The former workers confirmed that the reconstructed procedures resembled old routine dismantling. The workers pointed out that there were locomotives under maintenance regularly and that the dust hovered all over the workshop.

For the hygienic assessment of dismantling, eight personal air samples were collected and asbestos exposure was measured with standardised techniques. The average number of fibres $>5 \mu \mathrm{m}$ was $5 \cdot 0$ (range $2 \cdot 5-7 \cdot 5$ ) $/ \mathrm{cm}^{3}$, indicating medium exposure. The samples contained two types of asbestos-namely, anthophyllite and chrysotile fibres. Also, the type of asbestos exposure was analysed from the samples of insulation material of three demolished engines. The analysis of these samples indicated that anthophyllite was the main type of asbestos used in insulation material of boilers. Chrysotile was detected in woven strings around pipes and ventilators. Asbestos concentrations in cabins of diesel locomotives with asbestos insulation on exhaust pipes has been measured. The number of fibres was undetectable $(<0 \cdot 1$ fibres $/ \mathrm{cm}^{3}$ ). 
The concentration of benz(a)pyrene and dust exposure in rolling stock and during a journey was measured in the cabin of a renovated steam locomotive with standard occupational hygienic methods. While cleaning and declinkering a fire box, which took less than half an hour a day, the concentrations of benz(a)pyrene varied from 0.006 to 0.025 $\mu \mathrm{g} / \mathrm{m}^{3}$ and dust concentrations from 1.0 to 1.6 $\mathrm{mg} / \mathrm{m}^{3}$. During the journey the concentrations of benz(a)pyrene were lower, from 0.003 to $0.010 \mu \mathrm{g} / \mathrm{m}^{3}$. Dust concentrations varied from 0.7 to $2.8 \mathrm{mg} / \mathrm{m}^{3}$. Routine hygienic measurements in cabins of diesel engines and in rolling workshops in Finnish railways indicated that the concentrations of particles and benz(a)pyrene in diesel engines were similar to those in the steam engine. No nitrogen oxides were detected during steam engine operations, but according to routine hygienic measurements in Finnish railways the diesel engine drivers are exposed to nitrogen compounds emitted by the engines in the cabins and in rolling stock. 9

As well as the exposure directly linked to train operations, locomotive drivers were exposed to organic substances such as lubricating oils, coal tar (creosote), and coal.

\section{COHORT STUDY OF INCIDENCE OF CANCER}

The cancer risk of locomotive drivers was studied in a retrospective cohort study. The cohort consisted of all members of the Finnish Locomotive Drivers' Association between the years 1953 and 1991-that is, all Finnish drivers since 1953. Retired locomotive drivers remain members of the association up to their death. All drivers were men. The cohort consisted of 8693 members; 302 members (3.5\%) were excluded because of inadequate personal identification data. Follow up for

Table 1 Person-years under follow up among the 8391 Finnish locomotive drivers, 1953-91, by period and follow up time since first employment

\begin{tabular}{lllrr}
\hline \multirow{5}{*}{ Period } & \multicolumn{4}{l}{ Follow up time $(y)$} \\
\cline { 2 - 5 } & $0-14$ & $15-29$ & \multicolumn{1}{l}{$30+$} & \multicolumn{1}{c}{ Total } \\
\hline $1953-65$ & 35333 & 24101 & 7506 & 66940 \\
$1966-78$ & 14957 & 35756 & 18516 & 69229 \\
$1979-91$ & 25111 & 14655 & 36819 & 76585 \\
$1953-91$ & 75401 & 74512 & 62841 & 212754 \\
\hline
\end{tabular}

Table 2 Expected (Exp) and observed (Obs) numbers of cancer cases, 1953-91, among locomotive drivers and the standardised incidence ratios (SIR) with their $95 \%$ CIs, by site

\begin{tabular}{|c|c|c|c|c|}
\hline Primary site (ICD-7) & Obs & $\operatorname{Exp}$ & SIR & $(95 \% \mathrm{Cl})$ \\
\hline All sites $(140-204)^{\star}+$ & 915 & 962 & 0.95 & $(0.89-1 \cdot 01)$ \\
\hline $\begin{array}{l}\text { Oral cavity and pharynx }(143-148) \\
\text { Stomach }(151) \\
\text { Colon }(153) \\
\text { Rectum }(154) \\
\text { Lung and trachea }(162 \cdot 0-1) \\
\text { Mesothelioma }(162 \cdot 2,158) \\
\text { Prostate (177) } \\
\text { Kidney (180) } \\
\text { Bladder, ureter, urethra }(181 \cdot 0)^{\star} \\
\text { Skin melanoma }(190) \\
\text { Skin (non-melanoma) (191)† } \\
\text { Non-Hodgkin's lymphoma }(200,202) \\
\text { Hodgkin's disease (201) } \\
\text { Leukaemia (204) }\end{array}$ & $\begin{array}{r}17 \\
86 \\
36 \\
29 \\
236 \\
8 \\
122 \\
38 \\
48 \\
17 \\
32 \\
19 \\
7 \\
21\end{array}$ & $\begin{array}{r}10 \\
112 \\
37 \\
34 \\
274 \\
2 \\
109 \\
31 \\
44 \\
17 \\
21 \\
24 \\
8\end{array}$ & $\begin{array}{l}1 \cdot 75 \\
0 \cdot 77 \\
0.98 \\
0.85 \\
0.86 \\
4 \cdot 05 \\
1 \cdot 12 \\
1 \cdot 25 \\
1.08 \\
0.99 \\
1.53 \\
0.78 \\
0.83 \\
0 \cdot 87\end{array}$ & $\begin{array}{l}(1.02-2 \cdot 80) \\
(0.61-0.94) \\
(0.69-1.36) \\
(0.57-1 \cdot 22) \\
(0.75-0.97) \\
(1 \cdot 75-7.97) \\
(0.92-1.32) \\
(0.88-1.70) \\
(0.80-1.43) \\
(0.57-1.57) \\
(1.04-2.15) \\
(0.47-1.21) \\
(0.34-1.72) \\
(0.54-1.32)\end{array}$ \\
\hline
\end{tabular}

^ Excludes papillomas of the bladder.

†Excludes basal cell carcinomas of the skin death and emigration was performed in a record linkage with the Central Population Register of Finland.

The calculation of person-years started at the beginning of the membership or on 1 January 1953, whichever was later, and ended at death or emigration or on 31 December 1991, whichever occurred first.

At the Finnish Cancer Registry cancer cases of the cohort were identified by means of an automatic record linkage with a unique personal identification number assigned to everyone resident in Finland since the beginning of 1967. For those people who had died between 1953 and 1966 the follow up was performed manually with names, dates of birth, and places of residence as keys. The observed number of cases and person-years at risk were counted for five year age groups for three 15 year follow up periods since first employment, separately for 1953-65, 1966-78, and 1979-91. It should be noted that all the Finnish locomotive drivers start their training at about the same age, from 16 to 20. This means that there is no need to report results by both follow up time since first employment and age.

The expected numbers of cases for total cancer and for specific cancer types were calculated by multiplying the number of personyears in each age group by the corresponding average incidence of cancer in Finland during the period of observation. The specific cancer types selected for study were cancers earlier reported to be linked with asbestos or derivaties of coal and diesel combustion products including creosote. These are mouth and pharynx, stomach, colon, lung and trachea, mesothelioma, prostate, kidney, bladder, ureter and urethra, skin melanoma, skin (non-melanoma), lymphatic tissue (non-Hodgkin's), Hodgkin's disease, and leukaemia.

To calculate the standardised incidence ratio (SIR) for each group, the observed number of cases was divided by the expected number. Significance was tested by the Mantel-Haenszel $\chi^{2}$ test, on the presumption that the number of observed cases followed a Poisson distribution.

\section{Results}

The number of person-years under follow up for 8391 men in the cohort was 212800 (table 1). The mean duration of follow up was 25.4 years.

During the 38 year observation period, 915 cases of cancer were found; the expected number was 962 (table 2). The SIR for total cancer was significantly lower than expected only in the first period, 1953-65 (131 observed cases (Obs) $v 163$ expected (Exp), SIR $0.81,95 \%$ confidence interval $(95 \% \mathrm{CI}$ ) $0.67-0.94)$. In later periods the SIR for total cancer was close to unity. The reduction in the risk in the first period was totally attributable to cancers of the stomach (SIR 0.60, 21 Obs $v 35 \mathrm{Exp}, 95 \% \mathrm{CI} 0.37-0.92)$ and lung (SIR 0.64, 29 Obs $v 46$ Exp, 95\% CI 
Table 3 The observed (Obs) numbers of cancer cases and the standardised incidence ratios 1953-91 (SIRs) with their 95\% CIs for selected sites among Finnish locomotive drivers, 1953-91 by follow up time since first employment

\begin{tabular}{|c|c|c|c|c|c|c|c|c|c|}
\hline \multirow[b]{3}{*}{ Primary site (ICD-7) } & \multicolumn{9}{|c|}{ Follow up time $(y)$} \\
\hline & \multicolumn{3}{|c|}{$0-14$} & \multicolumn{3}{|c|}{$15-29$} & \multirow{2}{*}{$\begin{array}{l}\geqslant 30 \\
\text { Obs }\end{array}$} & \multirow[b]{2}{*}{ SIR } & \multirow[b]{2}{*}{$(95 \% C I)$} \\
\hline & Obs & SIR & $(95 \% C I)$ & Obs & SIR & $(95 \% C I)$ & & & \\
\hline All sites & 26 & 0.64 & $(0.42-0.93)$ & 190 & 0.96 & $(0 \cdot 83-1 \cdot 10)$ & 699 & 0.97 & $(0 \cdot 90-1 \cdot 03)$ \\
\hline $\begin{array}{l}\text { Oral cavity and pharynx } \\
\text { Lung and trachea } \\
\text { Mesothelioma } \\
\text { Kidney } \\
\text { Bladder, ureter, urethra } \\
\text { Skin (non-melanoma) }\end{array}$ & $\begin{array}{l}-6 \\
-\bar{c} \\
\overline{1}\end{array}$ & $\begin{array}{r}1 \overline{02} \\
0.05 \\
\overline{-} \\
0 . \overline{99}\end{array}$ & $\begin{array}{l}(0-6 \cdot 15) \\
(0 \cdot 37-2 \cdot 22) \\
(0-72 \cdot 6) \\
(0-4 \cdot 35) \\
(0-4 \cdot 94) \\
(0 \cdot 02-5 \cdot 49)\end{array}$ & $\begin{array}{r}4 \\
43 \\
9 \\
9 \\
6\end{array}$ & $\begin{array}{l}1.56 \\
0.73 \\
1.31 \\
1.35 \\
1.67\end{array}$ & $\begin{array}{l}(0.43-4.00) \\
(0.53-0.97) \\
(0.00-10.9) \\
(0.60-2.49) \\
(0.62-2.57) \\
(0.61-3.64)\end{array}$ & $\begin{array}{r}13 \\
187 \\
8 \\
29 \\
39 \\
25\end{array}$ & $\begin{array}{l}1.96 \\
0.89 \\
5.04 \\
1 \cdot 27 \\
1.05 \\
1.53\end{array}$ & $\begin{array}{l}(1 \cdot 05-3 \cdot 36) \\
(0.77-1.02) \\
(2 \cdot 18-9 \cdot 93) \\
(0.85-1 \cdot 82) \\
(0 \cdot 75-1 \cdot 43) \\
(0.99-2 \cdot 25)\end{array}$ \\
\hline
\end{tabular}

$0.43-0.91$ ). In the more recent observation periods the relative risk of lung cancer approached unity: The SIR was $0.87(95 \%$ CI $0.70-1.07)$ in $1966-78$ and $0.93(95 \%$ CI 0.77-1.10) in 1979-91.

No cases of mesothelioma were diagnosed during the first 30 years of follow up since first employment, but after that the risk was significantly increased (SIR 5.04, 95\% CI $2 \cdot 18-9 \cdot 93$, table 3).

The significantly increased risks for cancer of the oral cavity and pharynx (SIR 1.75) and for non-melanoma skin cancer (SIR 1.53) were due to the excess of cases after 15 years of follow up.

The SIR for other analysed cancers remained close to unity over the whole observation period and there were no systematic changes by follow up time.

\section{Discussion}

The 8391 locomotive drivers in our cohort form a homogeneous group starting their career at the same age and having similar training. The loss of $3.5 \%$ of the members of the original cohort due to inadequate identification data is likely to be non-systematic and therefore should not have caused any bias in the results. In the steam engine era they were exposed to asbestos during their two years of training. In traffic operations they were exposed to combustion products of the fuels of engines.

The reconstruction showed that the insulation of the boilers caused at least a medium exposure to asbestos. The dust hovered in the air all the working day. American ${ }^{10}$ and Swedish ${ }^{1}$ studies based on enquiries of working conditions obtained similar estimations of exposure. The mean fibre counts in asbestos textile factories in the late 1940s and early 1950s have been estimated to be 5-10 fibres $/ \mathrm{cm}^{3} .^{11}$

The levels of asbestos exposure in the railway workshops were typical of heavy industry from the 1920s to the 1970s. In Finland the main component was anthophylline produced in domestic mines. The exposure of locomotive drivers was not exclusively to anthophylline fibres as chrysotile was detected in samples taken around the pipes of locomotives. In minerological investigations in the Finnish asbestos mining area, the source of asbestos used in the railways, traces of tremolite have also been found. ${ }^{12}$
Amphibole varieties of asbestos have been considered to be the main causal agent of mesothelioma. ${ }^{13}$ Chrysotile has been shown to increase risk of lung cancer-for example, in asbestos textile operations. ${ }^{14}$ Also, increased risk of bronchial cancer occurs among anthophylline miners even when cigarette smoking is taken into account. ${ }^{15}$ The Finnish locomotive drivers have been exposed to anthophylline asbestos contaminated with chrysotile and tremolite.

Results of earlier studies that show an increased risk of mesothelioma among railway workers vary considerably due to differences in type of asbestos and duration and level of the exposure. Mancuso ${ }^{16}$ found that one in 13 machinists exposed to chrysotile developed mesothelioma, and mesothelioma constituted $34 \%$ of all cancer deaths. Railway occupations in the United States with regular asbestos exposure (skilled trades, steam locomotive repair) had an odds ratio of 21.4 , but the occupations with potential intermittent exposure (engineers) had a non-significant odds ratio of only $2 \cdot 3 .{ }^{17}$ In a Swedish cancer registry study an increased risk of $\mathbf{9 \cdot 5}$ (four cases observed) was found among workers working in the railway equipment manufacturing industry. ${ }^{18}$

Peto has stated that brief early exposure to asbestos may produce a substantial risk of mesothelioma but only a small increased risk of bronchial carcinoma, whereas 20 years of asbestos exposure from the age of 45 to 65 might increase the risk much more for bronchial carcinoma than for mesothelioma. ${ }^{19}$ The results of our study are consistent with this model. The short term medium exposure to asbestos seems to be associated with a relative risk of $\mathbf{4}$ for mesothelioma but the risk of lung cancer is not increased. The incidence of lung cancer was below the national average and there was no increase with increasing follow up since first employment.

In our cohort all the cases of mesothelioma occurred more than 30 years since first employment, and only one of eight cases was younger than 60 . This finding is similar to those reported earlier. The malignant consequences of asbestos exposure appear 30 to 40 years after exposure..$^{14} 172021$

Smoking is the most important non-occupational risk factor for mesothelioma and especially for lung cancer. The upward trend in the SIR of lung cancer from 0.6 in the 1950 s to 0.9 in the 1980 s in our study can be 
explained by changes in exposures (asbestos, combustion products) and in smoking habits. Smoking, diesel exhaust fumes, and asbestos have been suggested to have interactive effects on risk of lung cancer. ${ }^{22}$ Diesel locomotives, causing exposure to diesel exhaust, were introduced to the railways in the $1950 \mathrm{~s}$. The exposure to combustion products among locomotive drivers is, however, only slightly above the national average. The exposure to benz(a)pyrene is above that of Finnish town air. ${ }^{23}$ In a Swedish study of traffic workers with the same level of diesel exhaust exposure as Finnish locomotive drivers there were no detected signs of urinary mutagenicity or increased thioether excretion in urine. ${ }^{1}$

In the steam engine era Finnish locomotive drivers were not heavy smokers. Anecdotal evidence indicates that draughts in the cabin prevented drivers from appreciating smoking. It may be assumed that the increased smoking in the less draughty cabins of diesel locomotives with less physical work and more passive monitoring would have increased the risk of lung cancer close to the national average. A cross sectional study of Finnish locomotive drivers in the year 1976 showed that $40 \%$ of them were current smokers, $34 \%$ had stopped smoking, and $26 \%$ had never smoked. ${ }^{24}$ These percentages are similar to those of the whole Finnish population in $1979 .{ }^{25}$

Asbestosis insulation workers in the United States and Canada have an increased risk of death from cancers of the oesophagus, colon and rectum, larynx, oropharynx, kidney, and perhaps stomach. ${ }^{26}$ Our study showed an increased SIR for oropharyngeal cancer but not for the other sites, possibly due to different exposures. On the other hand our study shows an increased risk of non-melanoma skin cancer, consistent with other experiences, in occupational medicine. Locomotive drivers are exposed to different organic substances (lubricating oils, creosote) that can cause dermal irritation and toxidermia. ${ }^{27} \mathrm{~A}$ slight excess of squamous cell skin cancer has been found before among engine drivers ${ }^{28}$ and creosote exposed impregnators. ${ }^{29}$

Among the members of the Brotherhood of Locomotive Engineers in the United States there were significantly raised proportionate mortality ratios for cancers of the bladder $(2 \cdot 05)$, kidney $(2 \cdot 65)$, digestive organs $(1 \cdot 30)$, and lymphoreticular malignancies $(2 \cdot 05))^{4}$ Mortality ratios for the respiratory system were not increased. The increased risks of cancer of the lower urinary tract associated with occupational exposure of locomotive drivers has been confirmed by later studies, ${ }^{3} 30$ even when smoking was controlled for. ${ }^{5} \mathrm{We}$ found only slightly higher risks for cancers of the bladder (SIR 1.08) and kidney (SIR $1 \cdot 25$ ), which may, taking into account the low prevalence of smoking in our cohort, include a component of occupational aetiology.

In conclusion, the fourfold risk of mesothelioma in locomotive drivers is likely to be triggered by short term asbestos exposure. Also the increased incidence of non-melanoma skin cancer and oropharyngeal cancer might be work related. Because of the low prevalence of smoking in the steam engine era the risk of lung cancer has until now been clearly below the national average. The exposure to diesel engine exhaust fumes seems to be small and its role in causing cancer neglible. The classic occupational exposures have been waning with new working conditions and gradual electrification of the railways in the 1970 s and the 1980 s but this benefit is not strong enough to compensate for the increasing risks associated with modern working conditions including more enclosed cabins, more monitoring $_{s}$ and more smoking.

This work was funded by an Occupational Health Grant from the Treasury of Finland. We thank Hannu Riipinen MSc for exposure assessments and Matti Romo $M D$ and Heikk Hirvonen MD, Finnish State Railways, for their comments. We express our sincere thanks to Professor Nick Day and to the MRC Biostatistics Unit, Cambridge, for support in preparation of the report.

1 Ohlson C-G, Klaesson B, Hogstedt C. Mortality among asbestos-exposed workers in a railway workshop. Scand asbestos-exposed workers in a railway work Environ Health 1984;10:283-91.

2 Williams RR, Stegens NL, Goldsmith JR. Associations of cancer site and type with occupation and industry from third national cancer survey interview. F Natl Cancer Inst 1977;59:1147-85.

3 Vinels P, Simonoto L. Estimates of the proprotion of bladder cancers attributable to occupation. Scand $\mathcal{F}$ Work Environ Health 1986;12:55-60.

4 Schenk TW. A mortality study of locomotive engineers, Int-B. Buffalo, NY: State University of New York, 1989. (Dissertation.)

5 Schifflers E, Jamart J, Renard V. Tobacco and occupation as risk factors in bladder cancer: a case-control study in Southern Belgium. Int $₹$ Cancer 1987;39:287-92.

6 Whitaker CJ, Lee WR, Downes J. Squamous cell skin cancer in the Northwest of England, 1967-69, and its cancer in the Northwest of England, 1967-69, and

7 Karlehagen S, Andersen A, Ohlson C G. Cancer incidence among creosote-exposed workers. Scand $\mathcal{f}$ Work Environ Health 1992;18:26-9.

8 Viadana E, Bross IDJ, Houten L. Cancer experience of men exposed to inhalation of chemicals or to combustion products. $\mathcal{F}$ Occup Med 1976;18:787-92.

9 Heino M, Ketola R, Mäkelä P, Mäkinen R, Niemelä R, Starck J, Partanen T. Work conditions and health of locomotive engineers. I. Noise, vibration, thermal climate, diesel exhaust constituents, ergonomics. Scand ₹ Work Environ Health 1978;4(suppl 3):3-14.

10 Nicholson WJ, Perkel G, Selikof IJ. Occupational exposure to asbestos: population at risk and projected mortalityto asbestos: population at risk and projected

11 Berry G, Lewissohn HC. Dose-response relationships for asbestos related disease: implications for hygienic asbestos related disease: implications for

12 Karialainen A, Meurman L, Pukkala E. Four cases of mesothelioma among Finnish anthophylline miners. Occup Environ Med 1994;51:212-5.

13 Pelnar PV. Further evidence of nonasbestos-related mesothelioma, a review of literature. Scand $\mathcal{f}$ Work Environ Health 1988;14:141-4.

14 Dement JM, Harris RL, Symons MJ, Shy CM. Exposures and mortality among chrysotile asbestos workers. Part II: Mortality. Am $\mathcal{A}$ Ind Med 1983;4:421-33.

15 Meurman LO, Kiviluoto R, Hakama M. Combined effect of asbestos exposure and tobacco smoking on Finnish anthophylline miners and millers. Ann NY Acad $S_{c i}$ 1979;330:491-5.

16 Mancuso TF. Relative risk of mesothelioma among railroad workers exposed to chrysotile. Am $\mathcal{f}$ Ind Med road workers expc

17 Schenker MB, Garshick, et al. A population-based casecontrol study of mesothelioma deaths among U.S. control study of mesothelioma deaths among U.S.

18 Malker HSR, Mclaughlin JK, Malker BK, Stone BJ, Weiner JA, Erikson JLE, Blot WJ. Occupational risks for pleural mesothelioma in Sweden, 1961-1979. I Natl Cancer Inst 1985;74:61-6.

19 Peto J. Dose-response and mortality. Dose response relationship for asbestos related disease: implications for hygienic standards. Ann NY Acad Sci 1979;330: 195-203.

20 Jones RD, Smith DM Thomas PG. Mesothelioma in Britain in 1968-1983. Scand $\mathcal{f}$ Work Environ Health 1988;14:145-52.

21 Bignon J, Sebastien P, Di Menza L, Payan H. French mesothelioma register. Ann NY Acad Sci 1979;330: 455-66. 
22 Emmelin A, Nyström L, Wall S. Diesel exhaust exposure and smoking: a case referent study of lung cancer among and smoking: a case referent study of lung cancer am

23 Oulu city council, Department of environmental hygiene. Polycyclic aromatic hydrocarbons in air of Oulu 1982-1983. Oulu: Oulu city council, 1985. (In Finnish.)

24 Finnish Institute of Occupational Medicine. Locomotive driver study 3. Helsinki: 1976. (In Finnish.)

25 Kurkela R. Smoking after the Smoking Act. Helsinki Central Statistical Office of Finland, 1987. (In Finnish.)

26 Selikoff JI, Seidman H. Asbestosis associated death among insulation workers in the United States and Canada 1967-1987, in the book third wave of asbestos disease: exposure to asbestosis in working place, public health control, Ann NY Acad Sci 1993;643:1-14.

27 Merlescu G. Toxidermies cutanees chez les ouvries de erlescu G. Toxidermies cutanees chez les ouvries de chemin de fer. Revue Suisse de Medicine. 1974;29:902-4. Whitaker CJ, Lee WR, Downes J. Squamous cell skin can-
cer in the northwest of England, 1967-69, and its relacer in the northwest of England, 1967-69, and

29 Karlehagen S, Andersen A, Ohlson C G. Cancer incidence among creosote-exposed workers. Scand $\mathcal{F}$ Work Environ Health 1992;18:26-9.

30 Claude JC, Frentzel-Beyme RR, Kunze E. Occupation and risk of cancer of the lower urinary tract among men. A case control study. Int $f$ Cancer 1988;41:371-9.

\section{Correspondence and editorials}

Occupational and Environmental Medicine welcomes correspondence relating to any of the material appearing in the journal. Results from preliminary or small scale studies may also be published in the correspondence column if this seems appropriate. Letters should be not more than 500 words in length and contain a minimum of references. Tables and figures should be kept to an absolute minimum. Letters are accepted on the understanding that they may be subject to editorial revision and shortening.

The journal also publishes editorials which are normally specially commissioned. The Editor welcomes suggestions regarding suitable topics; those wishing to submit an editorial, however, should do so only after discussion with the Editor. 